\title{
Organocatalytic Asymmetric Annulation of 1,3-Bis(alkoxycarbonyl)buta-1,3-dienes and Aldehydes
}

\author{
Bernardo Pezzati, ${ }^{\dagger, \ddagger}$ Mathieu F. Chellat, ${ }^{\dagger}$ John J. Murphy, ${ }^{\S}$ Céline Besnard," \\ Gianna Reginato, ${ }^{\ddagger}$ John C. Stephens, ${ }^{\S}$ and Alexandre Alexakis ${ }^{*, \dagger}$
}

Department of Organic Chemistry, University of Geneva, quai Ernest Ansermet 30, CH-1211 Geneva 4, Switzerland, Istituto di Chimica dei Composti Organometallici, ICCOM-CNR, via Madonna del Piano 10, Sesto Fiorentino - (Fi), 50019 Italy, Department of Chemistry, National University of Ireland Maynooth, County Kildare, Ireland, and Laboratory of Crystallography, University of Geneva, quai Ernest Ansermet 24, CH-1211 Geneva 4, Switzerland

alexandre.alexakis@unige.ch

Received April 15, 2013

\section{ABSTRACT}
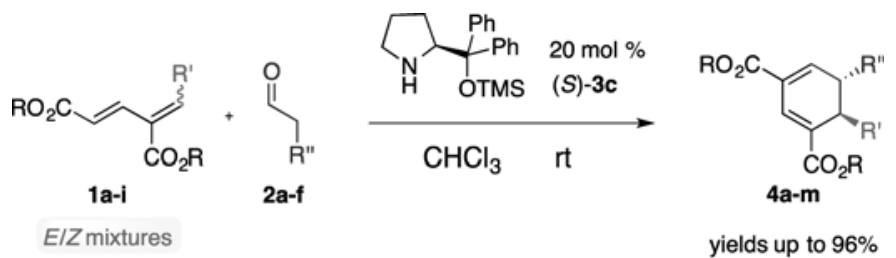

yields up to $96 \%$ ee up to $99.5 \%$ dr up to $20 / 1$

Asymmetric organocatalytic annulation of E/Z isomeric mixtures of bis(alkyl carboxylate)buta-1,3-dienes and aldehydes has been realized via enamine catalysis. In the presence of $\alpha, \alpha$-diphenyl-2-pyrrolidinemethanol trimethylsilyl ether, excellent stereo- and enantioselectivities were achieved for a broad spectrum of substrates.

The development of highly efficient asymmetric catalytic synthesis leading to enantiomerically enriched building blocks ${ }^{1}$ represents one of the most important tasks of the modern organic chemist. In this research area, organocatalysis has emerged as one of the best approaches used in pursuit of this goal due to mild operative conditions, easy combination in cascade processes, and complementary reactivity to transition-metal catalysis. ${ }^{2}$ In particular,

\footnotetext{
${ }^{\dagger}$ Department of Organic Chemistry, University of Geneva.

* Istituto di Chimica dei Composti Organometallici.

${ }^{\S}$ Department of Chemistry, National University of Ireland Maynooth.

" Laboratory of Crystallography, University of Geneva.

(1) Hanessian, S. Total Synthesis of Natural Products: The 'Chiron' Approach; Pergamon: Oxford, 1983.

(2) Selected reviews on organocatalysis: (a) Mukherjee, S.; Yang, J. W.; Hoffmann, S.; List, B. Chem. Rev. 2007, 107, 5471. (b) Dalko, P. I.; Moisan, L. Angew. Chem., Int. Ed. 2004, 43, 5138. (c) Bertelsen, A.; Jørgensen, K. A. Chem. Soc. Rev. 2009, 38, 2178.

(3) General reviews on asymmetric aminocatalysis: (a) Melchiorre, P.; Marigo, M.; Carlone, A.; Bartoli, G. Angew. Chem., Int. Ed. 2008, 47, 6138. (b) Bertelsen, S.; Jørgensen, K. A. Chem. Soc. Rev. 2009, 38, 2178. (c) MacMillan, D.W. C. Nature 2008, 455, 304
}

asymmetric conjugated addition of carbonyl compounds to electron-poor olefins has been broadly exploited to build high value chiral synthons with excellent stereo- and enantioselectivity. ${ }^{3}$ In contrast, the application of activated dienes in asymmetric enamine catalysis is still poorly investigated. Over the last few of years, the application of electron-poor butadienes in inverse-electron-demand Diels-Alder reactions via asymmetric enamine and dienamine catalysis has been reported. ${ }^{4}$ Recently, our research group has described an exciting new reactivity involving a well-designed 1,3-bis(sulfonyl)butadiene in asymmetric 1,6-conjugated addition of aldehydes with excellent regio- and stereoselectivity followed by rapid in situ cyclization. ${ }^{5}$ This new process gives access to interesting chiral polysubstituted cyclohexa-1,3-diene intermediates.

(4) (a) Jiang, X.; Fu, D.; Shi, X.; Wang, S. Chem. Commun. 2011, 47, 8289. (b) Li, J.-L.; Kang, T.-R.; Zhou, S.-L.; Li, R.; Wu, Li.; Chen, Y.-C. Angew. Chem., Int. Ed. 2010, 49, 6418

(5) Murphy, J. J.; Quintard, A.; McArdle, P.; Alexakis, A.; Stephens, J. C. Angew. Chem., Int. Ed. 2011, 50, 1. 
There is still a large demand for the development of new efficient Michael acceptors in order to extend the scope of this fascinating reactivity and to better understand the mechanism of reaction. Therefore, we directed our efforts toward the study of easily accessible 1,3-activated dienes with a focus on 4-substituted 1,3-bis(alkyl carboxylate) butadienes that can be simply obtained through a single step Knoevenagel condensation from commercial glutaconic esters and aldehydes, although this reaction leads to dienes as mixtures of stereoisomers. ${ }^{6}$

We began our investigation using $\mathbf{1 a}$ as a single isomer model diene and isovaleraldehyde (Table 1). This test reaction was carried out in the presence of $20 \mathrm{~mol} \%$ of proline-based organocatalysts $\mathbf{3 a}-\mathbf{d}$ and at low concentration of the diene (Table 1).

Table 1. Screening of Organocatalysts and Optimization of the Reaction Conditions ${ }^{a}$<smiles>CCOC(=O)C=CC(=Cc1ccccc1)OCC</smiles>

$1 \mathbf{a}$

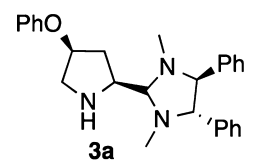<smiles>CC(C)CC=O</smiles>

2a

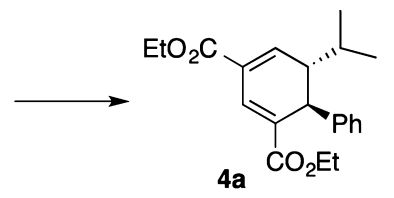

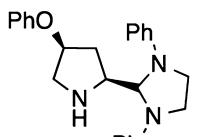

3b $\mathrm{Ph}^{\prime}$

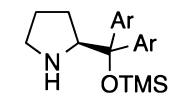

$3 \mathrm{c} \mathrm{Ar}=\mathrm{Ph}$

3d $\mathrm{Ar}=3,5-\left(\mathrm{CF}_{3}\right)_{2} \mathrm{C}_{6} \mathrm{H}_{3}$

\begin{tabular}{|c|c|c|c|c|c|c|}
\hline entry & cat. & $\begin{array}{c}\text { time } \\
\text { (h) }\end{array}$ & solvent & additive & $\begin{array}{c}\operatorname{conv}^{b} \\
(\%)\end{array}$ & $\begin{array}{l}\mathrm{ee}^{c} \\
(\%)\end{array}$ \\
\hline 1 & $\mathbf{3 a}$ & 48 & $\mathrm{CHCl}_{3}$ & none & 45 & 90 \\
\hline 2 & $\mathbf{3 b}$ & 48 & $\mathrm{CHCl}_{3}$ & none & 36 & 49 \\
\hline 3 & $3 \mathbf{c}$ & 48 & $\mathrm{CHCl}_{3}$ & none & 48 & $>99$ \\
\hline 4 & 3d & 48 & $\mathrm{CHCl}_{3}$ & none & 0 & nd \\
\hline 5 & $\mathbf{3 c}$ & 48 & toluene & none & 12 & nd \\
\hline 6 & $\mathbf{3 c}$ & 48 & $\mathrm{H}_{2} \mathrm{O} / \mathrm{EtOH}^{d}$ & none & 70 & 96 \\
\hline 7 & $\mathbf{3 c}$ & 48 & $\mathrm{CHCl}_{3}$ & $\mathrm{BzOH}$ ( 0.4 equiv) & 34 & 98 \\
\hline 8 & $3 \mathbf{c}$ & 48 & $\mathrm{CHCl}_{3}$ & $\mathrm{AcOH}$ ( 0.4 equiv) & 33 & 94 \\
\hline $9^{e}$ & $3 \mathbf{c}$ & 48 & $\mathrm{CHCl}_{3}$ & none & 60 & $>99$ \\
\hline $10^{f}$ & $3 \mathbf{c}$ & 120 & $\mathrm{CHCl}_{3}$ & none & $>99$ & $>99$ \\
\hline
\end{tabular}

${ }^{a}$ Reaction conditions (entry 1-9): 20 mol \% of catalyst, low concentration of the substrate $(0.15 \mathrm{M})$, and 10 equiv of isovaleraldehyde at room temperature. ${ }^{b}$ Determined by ${ }^{1} \mathrm{H}$ NMR on the crude mixture. ${ }^{c}$ Determined by chiral SFC. ${ }^{d}$ Relative ratio $=20 / 1 .{ }^{e} \mathbf{1 a}$ as $E / Z$ mixture $=40 / 60 .{ }^{f}$ Reaction conditions: $20 \mathrm{~mol} \%$ of catalyst, concentration of the substrate $(0.5 \mathrm{M})$, and 4 equiv of isovaleraldehyde and $1 \mathbf{a}$ as $E / Z$ mixture $=40 / 60$.

Aminal-pyrrolidine (APY) catalyst 3a, recently developed by our group, ${ }^{7}$ in $\mathrm{CHCl}_{3}$ led to optically active cyclohexa-1,3-diene 4a with promising $45 \%$ conversion and high stereocontrol (90\% ee, entry 1). Slightly lower

(6) (a) Hourcade, S.; Ferdenzi, A.; Retailleau, P.; Mons, S.; Marazano, C. Eur. J. Org. Chem. 2005, 7, 1302. (b) Henrich, F. Chem. Ber. 1902, 35 (2), 1663.

(7) (a) Quintard, A.; Bournaud, C.; Alexakis, A. Chem-Eur. J. 2008, 14, 7504. (b) Quintard, A.; Belot, S.; Marchal, E.; Alexakis, A. Eur. J. Org. Chem. 2010, 927. (c) Quintard, A.; Alexakis, A. Chem. Commun. 2010, 46, 4085. (d) Quintard, A.; Lefranc, A.; Alexakis, A. Org. Lett. 2011, 13, 1540. (e) Quintard, A.; Langlois, J.-B.; Emery, D.; Mareda, J.; Guénée, L.; Alexakis, A. Chem.-Eur. J. 2011, 17, 13433.

conversion and moderate enantioselectivity was observed with the same class of organocatalyst $\mathbf{3 b}$ (entry 2). Using $\alpha$, $\alpha$-diphenyl-2-pyrrolidinemethanol trimethylsilyl ether $\mathbf{3 c}$ (entry 3), 48\% conversion and excellent $99 \%$ ee was achieved, while the strongly electron-withdrawing 3,5-bis(trifluoromethyl)aryl-substituted catalyst $\mathbf{3 d}^{8}$ did not produce any conversion (entry 4). After this short screening of aminocatalysts, the reaction conditions were optimized using catalyst 3c. A drastic decrease of reactivity was observed in apolar solvents such as toluene (entry 5), while a $5 \% \mathrm{v} / \mathrm{v}$ aqueous solution of ethanol appeared to be the best media both in terms of conversion and stereoselectivity (entry 6). Unfortunately, due to increased formation of aldehyde byproducts this solvent mixture was not further used. Acid additives such as $\mathrm{BzOH}$ or $\mathrm{AcOH}$ had unfavorable consequences on the reaction rate (entries 7 and 8). Surprisingly, when substrate 1a was employed as mixture of isomers $4 E / 4 Z$ in combination with $3 \mathbf{c}$ in $\mathrm{CHCl}_{3}$ no negative impact on stereoselectivity was recorded, and the conversion was slightly increased (entry 9). This last result opened the opportunity to use stereoisomeric mixture of 4-aryl-substituted 1,3-bis(alkyl carboxylate) butadienes as substrates for this reaction, avoiding time-consuming and solvent spending separations. Finally, quantitative transformation of 1a was achieved by increasing the concentration of the substrate $(0.5 \mathrm{M})$ and the reaction time (entry 10$)$ while lowering the amount of aldehyde to 4 equiv.

Having these optimized conditions in hand, we started exploring the scope and the limitation of this transformation.

Table 2. Scope of Aldehydes for Organocatalytic Annulation ${ }^{a}$

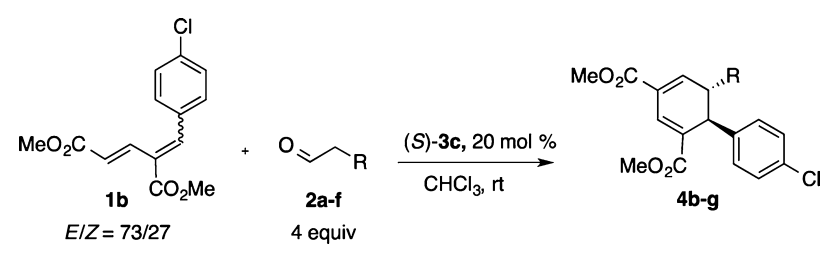

\begin{tabular}{llrlcc}
\hline entry & aldehyde & time $(\mathrm{h})$ & yield $^{b}(\%)$ & $\mathrm{ee}^{c}(\%) \mathrm{dr}(\operatorname{trans} / \mathrm{cis})^{d}$ \\
\hline 1 & $\mathrm{R}=i \mathrm{Pr}$ & 48 & $77, \mathbf{4 b}$ & 99 & $>20 / 1$ \\
$2^{e}$ & $\mathrm{R}=i \mathrm{Pr}$ & 72 & $95,($ ent $) \mathbf{4 b}$ & -99 & $>20 / 1$ \\
3 & $\mathrm{R}=\mathrm{Et}$ & 72 & $95, \mathbf{4 c}$ & 99 & $>20 / 1$ \\
4 & $\mathrm{R}=n \mathrm{Pr}$ & 96 & $92, \mathbf{4 d}$ & $>99$ & $>20 / 1$ \\
5 & $\mathrm{R}=n$ Pent & 120 & $74, \mathbf{4 e}$ & 99 & $>20 / 1$ \\
6 & $\mathrm{R}=\mathrm{Bn}$ & 72 & $76, \mathbf{4 f}$ & 97.7 & $>20 / 1$ \\
7 & $(S)$ - citronellal & 72 & $92, \mathbf{4 g}$ & & $>20 / 1$ \\
8 & rac-citronellal $^{f}$ & 72 & $($ conv $=81 \%)$ & $\mathbf{4 g}$ & $2.7 / 1$
\end{tabular}

${ }^{a}$ Reaction conditions: $20 \mathrm{~mol} \%$ of catalyst $\mathbf{3 c}$, concentration of the substrate $(0.5 \mathrm{M}), 4$ equiv of isovaleraldehyde and $\mathbf{1 b}$ as $E / Z$ mixture $=$ $73 / 27 .{ }^{b}$ Isolated yield. ${ }^{c}$ Determined by chiral SFC. ${ }^{d}$ Determined by ${ }^{1} \mathrm{H}$ NMR analysis. ${ }^{e}(R)-3 \mathbf{c}$ as catalyst, product $\mathbf{4 b}(R, R) .{ }^{f} 8$ equiv of raccitronellal was used.

(8) On the applications of catalysts $\mathbf{3 c}$ and 3d: (a) Marigo, M.; Wabnitz, T. C.; Fielenbach, D.; Jorgensen, K. A. Angew. Chem., Int. Ed. 2005, 44, 794. (b) Hayashi, Y.; Gotoh, H.; Hayashi, T.; Shoji, M. Angew. Chem., Int. Ed. 2005, 44, 4212. (c) Franzén, J.; Marigo, M.; Fielenbach, D.; Wabnitz, T. C.; Jorgensen, K. A. J. Am. Chem. Soc. 2005, 127, 18296. (d) Xu, L. W.; Li, L.; Shi, Z.-H. Adv. Synth. Catal. 2010, 352, 243. 
The variation of aldehydes was carried out on butadiene $\mathbf{1 b}$, slightly more reactive than $\mathbf{1 a}$, as a mixture of stereoisomers (Table 2).

Full conversion of starting material $\mathbf{1 b}$ was obtained with linear alkyl chain aldehydes and isovaleraldehyde in 3-4 days together with perfect stereoselectivity $(\mathbf{4 b}-\mathbf{e}$, entries 1-5). 3-Phenylpropanal reacted slower (yield = $76 \%$ after 120 h) with $97.7 \%$ ee (entry 6), while neither 3-tert-butylpropanal nor phenylacetaldehyde reacted, showing the great influence that steric and electronic properties of aldehydes have on this reaction. Using $(S)$ citronellal together with $(S)$-3c delivered substituted cyclohexadiene $\mathbf{4 g}$ as a single diastereoisomer after 3 days. In order to try to use this transformation to perform kinetic resolutions of chiral $\beta$-branched aldehydes, a test reaction was carried out with racemic citronellal but the product $\mathbf{4 g}$ was obtained in lower conversion and with a $\mathrm{dr}=2.7 / 1$ even after increasing the amount of aldehyde to 8 equivalents. The scope of the substrate was then investigated by reacting different 4-aryl-1,3-bis(alkyl carboxylate)butadienes 1a-f as mixtures of $E / Z$ stereoisomers (Table 3 ), with isovaleraldehyde, in the presence of $20 \mathrm{~mol} \%$ of organocatalyst $\mathbf{3} \mathbf{c}$ in $\mathrm{CHCl}_{3}$.

Table 3. Scope of Substrate for Organocatalytic Annulation ${ }^{a}$

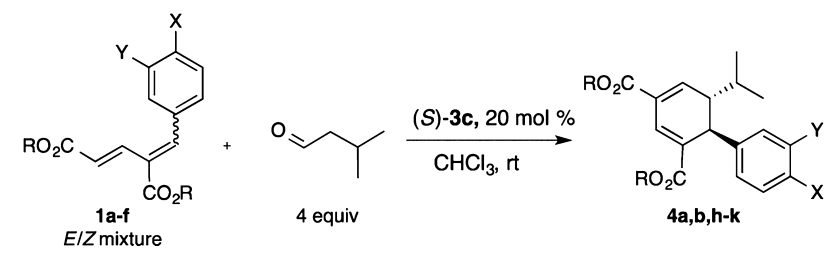

\begin{tabular}{ccccccccc}
\hline entry & $\mathrm{X}$ & $\mathrm{Y}$ & $\mathrm{R}$ & $E / Z^{b}$ & time $(\mathrm{h})$ & $\operatorname{yield}^{c}(\%)$ & ee $^{d}(\%)$ & $\mathrm{dr}(\operatorname{trans} / \text { cis })^{f}$ \\
\hline 1 & H & H & Et & $40 / 60$ & 120 & $82, \mathbf{4 a}$ & $>99$ & $>20 / 1$ \\
$2^{e}$ & $\mathrm{Cl}$ & H & Me & $73 / 27$ & 72 & $95, \mathbf{4 b}$ & -99 & $>20 / 1$ \\
3 & Br & H & Me & $78 / 22$ & 48 & $66, \mathbf{4 h}$ & $>99$ & $>20 / 1$ \\
$4^{e}$ & H & Br Me & $79 / 21$ & 72 & $94, \mathbf{4 i}$ & -97 & $>20 / 1$ \\
$5^{e}$ & F & H & Me & $80 / 20$ & 72 & $93, \mathbf{4 j}$ & -99 & $>20 / 1$ \\
6 & OMe H & Me $76 / 24$ & 240 & $66, \mathbf{4 k}$ & $>99$ & $>20 / 1$
\end{tabular}

${ }^{a}$ Reaction conditions: $20 \mathrm{~mol} \%$ of catalyst, concentration of the substrate $=0.5 \mathrm{M}, 4$ equiv of isovaleraldehyde. ${ }^{b}$ Starting material $E / Z$ ratio. ${ }^{c}$ Isolated yield. ${ }^{d}$ Determined by chiral SFC. ${ }^{e}$ Using $20 \mathrm{~mol} \%$ of $(R)$-3c. ${ }^{f}$ Determined by ${ }^{1} \mathrm{H}$ NMR analysis.

When buta-1,3-dienes with electron-withdrawing aryl groups at the 4-position were used (entries 3-5) products $\mathbf{4 h}-\mathbf{j}$ were obtained with full conversion after $2-3$ days. This transformation is still compatible with substrates containing an electron-donating group on the aryl ring such as $p$-methoxy (entry 6), but it requires a very long reaction time to generate a good isolated yield $(66 \%$ after 10 days). Remarkably, in all entries (1-6) perfect enantioselectivities were observed and in crude mixtures and isolated products only trans diastereoisomers could be observed. Therefore, asymmetric annulation of $4 E / 4 Z$ mixtures of 4-aryl-1,3-bis(alkyl carboxylate)butadienes and aldehydes appears to be a stereoconvergent process.
Interestingly, we noticed that catalyst $\mathbf{3} \mathbf{c}$ in $\mathrm{CDCl}_{3}$ is able to slowly isomerize different mixtures of stereoisomers of diene 1a (Scheme 1). ${ }^{9}$ In addition, when comparing the yields of entries 3 and 9 (Table 1) it seems that 4Z-aryl-1,3bis(ester)buta-1,3-dienes react faster than $4 E .^{10}$

Scheme 1. Catalyst-Induced Isomerization of Substrate

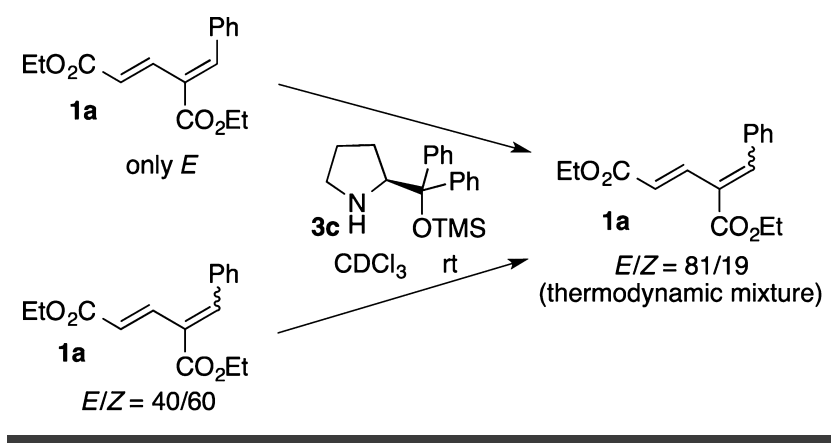

Finally, we expanded the reaction to 4-alkyl-1,3-bis(alkyl carboxylate) butadienes $\mathbf{1 g}, \mathbf{h}$, which were also used as mixtures of $E / Z$ stereoisomers (Table 4 ). These substrates still react with excellent enantiocontrol despite lower diastereoselectivities.

Table 4. Scope of Substrate for Organocatalytic Annulation ${ }^{a}$

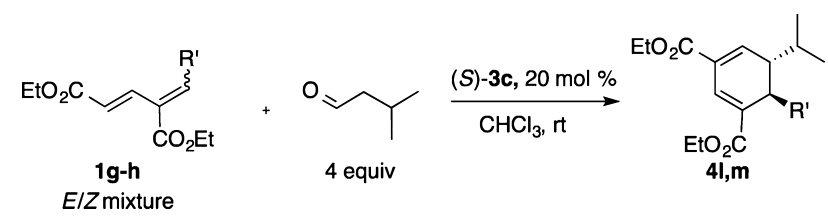

\begin{tabular}{ccccccc}
\hline entry & $\mathrm{R}^{\prime}$ & $E / Z^{b}$ & time $(\mathrm{h})$ & $\operatorname{yield}^{c}(\%)$ & $\mathrm{ee}^{d}(\%)$ & $\mathrm{dr}(\operatorname{trans} / \mathrm{cis})^{e}$ \\
\hline 1 & $\mathrm{Et}$ & $85 / 15$ & 72 & $81, \mathbf{4 1}$ & 97 & $85 / 15$ \\
2 & $i \mathrm{Bu}$ & $69 / 31$ & 48 & $58, \mathbf{4 m}$ & 99 & $88 / 12$
\end{tabular}

${ }^{a}$ Reaction conditions: $20 \mathrm{~mol} \%$ of catalyst, concentration of the substrate $=0.5 \mathrm{M}, 4$ equiv of isovaleraldehyde. ${ }^{b}$ Starting material $E / Z$ ratio. ${ }^{c}$ Isolated yield. ${ }^{d}$ Determined by chiral SFC. ${ }^{e}$ Determined by ${ }^{1} \mathrm{H}$ NMR analysis.

The absolute configuration of the products was confirmed unambiguously via X-ray crystallographic analysis of cyclohexa-1,3-diene $4 \mathbf{i}$ to be $(5 R, 6 R)$ (Figure 1$)$. The relative configuration of all cyclohexa-1,3-dienes was also determined by ${ }^{1} \mathrm{H}$ NMR and COSY analysis to be trans.

In an effort to see if this methodology could be applied to 1,1-bis(alkyl carboxylate)butadienes, the diester 5 was synthesized by Knoevenagel condensation between diethyl malonate and cinnamaldehyde. Unfortunately, when $\mathbf{5}$ was reacted with bulky catalysts $\mathbf{3 c}, \mathbf{d}$ no conversion could be observed (Scheme 2). Switching to less sterically hindered

(9) See the mechanism study on related amine-promoted MaleateFumarate isomerization: Nozaki, K. J. Am. Chem. Soc. 1941, 63, 2681.

(10) Entries 3 versus 9 (Table 1) and Supporting Information. 

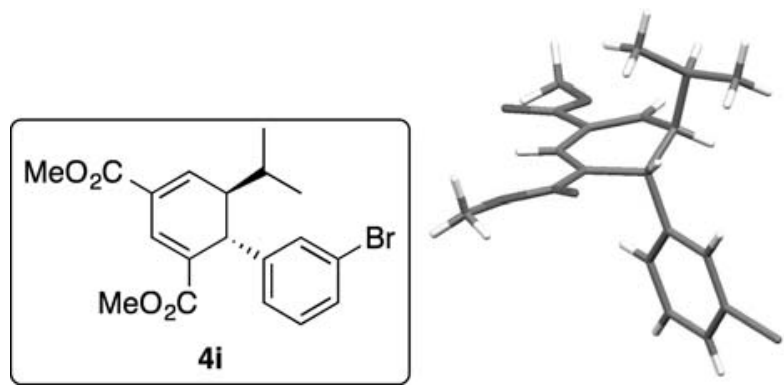

Figure 1. X-ray crystallographic analysis of cyclohexa-1,3-diene 4i.

catalysts, such as pyrrolidine or (2-pyrrolidinylmethyl)pyrrolidine, the only reaction observed was a retroKnoevenagel reaction to release cinnamaldehyde and diethyl malonate which could then react with isovaleraldehyde $\mathbf{2}$ a to give the corresponding conjugated malonate. ${ }^{11}$

Scheme 2. Reaction with Alkylidene Malonate 5

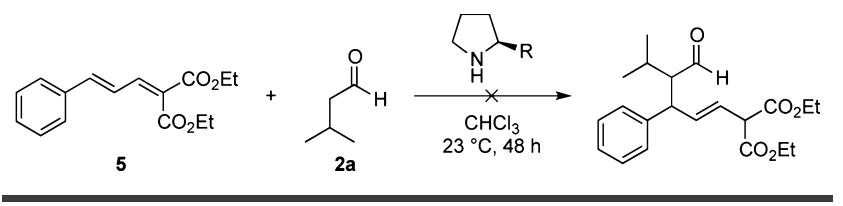

We can hypothesize that the mechanism of this transformation can be explained through a regio- and stereoselective 1,6-conjugated Michael addition followed by rapid cyclization and elimination of the catalyst ${ }^{3}$ (Scheme 3; pathway a). From a stereoselectivity point of view, when $(S)$-3c is used, the unshielded $S i$ face of the reactive enamine intermediate can attack the $S i$ face of both stereoisomers of 4-aryl-1,3-bis(ester)buta-1,3-dienes following the extended acyclic synclinal model of Seebach and Goliński for enamine conjugated attack. ${ }^{12}$ Alternatively, the same products can be obtained through isomerization of the substrate followed by a concerted inverseelectron demand Diels-Alder in an endo fashion and elimination of the organocatalyst (Scheme 3; pathway b).

In order to gain insight into the mechanism, test substrate $\mathbf{6}$ was synthesized with a blocked s-trans configuration (Figure 2). Unfortunately, this adduct was completely unreactive using the optimized conditions and could therefore not provide any useful information on the mechanism.

(11) Mossé-Sulzer, S.; Alexakis, A.; Mareda, J.; Bollot, G.; Bernardinelli, G.; Filinchuk, Y. Chem.-Eur. J. 2009, 15, 3204.

(12) Seebach, D.; Goliński, J. Helv. Chim. Acta 1981, 64, 1413.
Scheme 3. Possible Mechanisms for the Annulation Reaction

a)

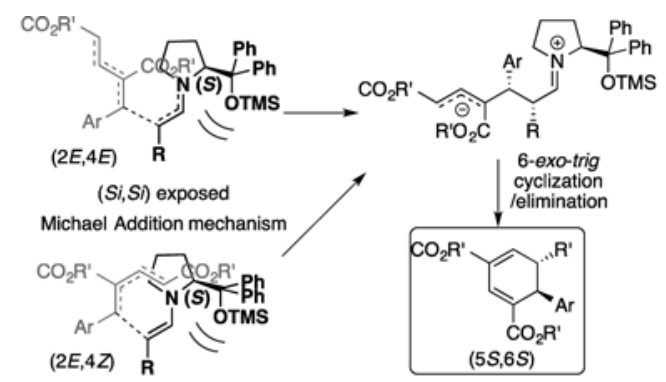

b)

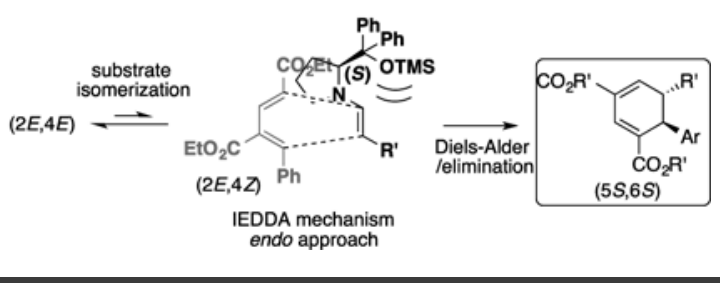

Figure 2. Substrate with blocked s-trans configuration.

In conclusion we developed an application of novel efficient activated-dienes in high stereoselective annulation reactions with aldehydes via enamine catalysis. This transformation led to new valuable enantioenriched cyclohexa1,3-dienes building blocks. Moreover, 4-substituted-1,3bis(alkyl carboxylate)butadienes could be used in this process as a stereoisomeric mixture in a stereoconvergent fashion.

Acknowledgment. This research was supported by the Swiss National Research Foundation (Grant No. 200020 144344) and COST action CM905 "Organocatalysis" (SER Contract No. C11.0080). We also thank the Irish Research Council (IRC) and NUI Maynooth for funding.

Supporting Information Available. Experimental procedures, NMR spectra, and chiral separations for all compounds. This material is available free of charge via the Internet at http://pubs.acs.org.

The authors declare no competing financial interest. 